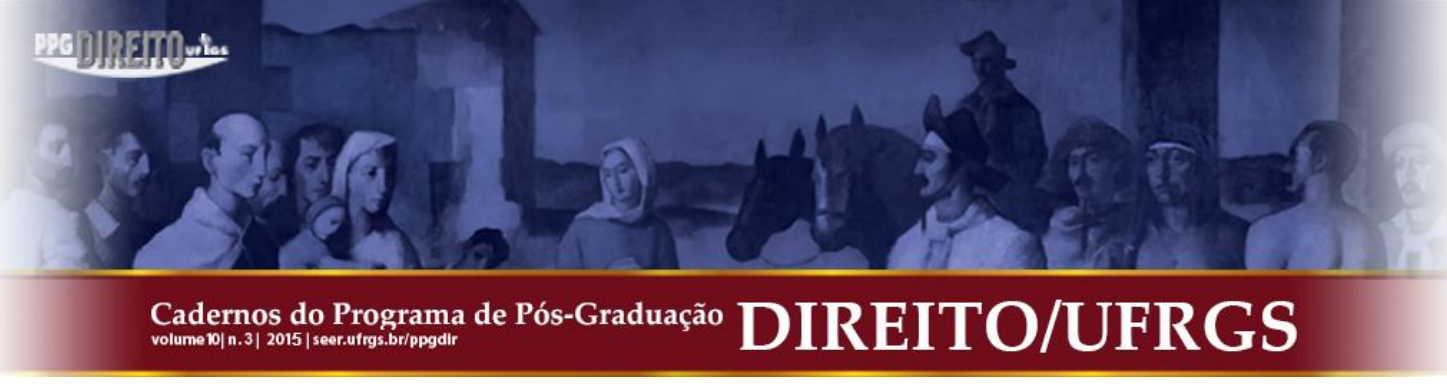

\title{
LIBERDADE, IDENTIDADE E DIREITO: SOBRE A INDELÉVEL MARCA HUMANA EM PHILIP ROTH
}

\author{
FREEDOM, IDENTITY, AND LAW: ON THE INDELIBLE HUMAN STAIN IN PHILIP
}

ROTH

\begin{abstract}
RESUMO: A partir do romance A Marca Humana, de Philip Roth, esse texto pretende discutir como o direito pode assegurar às pessoas a possibilidade de redefinirem sua identidade, especialmente diante das múltiplas formas de discriminação racial, social e religiosa existentes nas sociedades contemporâneas. Partindo da configuração moderna de que o indivíduo é sujeito capaz de autorreflexão e crítica, escolhemos o protagonista de Philip Roth para mostrar que o homem das democracias atuais tem a capacidade de se comportar reflexivamente em relação à própria subjetividade, endossando valores ou libertando-se de compromissos. Nessa última hipótese, é preciso garantir-lhe o direito de "pular fora".
\end{abstract}

PALAVRAS-CHAVE: Identidade. Discriminação Racial. Direito de "pular fora".

Gisele Cittadino*

ABSTRACT: From the Human Stain, a novel written by Philip Roth, this text intends to discuss how law can assure people the possibility to redefine their identity, especially considering the multiples forms of racial, social, and religious discriminations that exists in the contemporary societies. Starting from the modern configuration that the individual is a subject capable of selfreflection and criticism, we choose the leading figure of Philip Roth's novel to show that the human being in the modern democracies has the ability to behave reflectively regarding their own subjectivity, endorsing values or freeing up from commitments. In this latter hypothesis, it is needed to ensure him the right to "step out".

KEYWORDS: Identity. Racial Discrimination. Right to Step Out. SUMÁRIO: 1. A Marca Humana. 2. Tragédia, Identidade e Traição. 3. Autonomia ou o Direito de "Pular Fora". Referências.

\section{A MARCA HUMANA ${ }^{1}$}

Coleman Silk é professor de literatura clássica na Universidade de Athena, na Nova Inglaterra. Com 70 anos, branco, judeu, foi o responsável - como decano nas últimas quatro décadas - por uma revolução na instituição, recrutando jovens professores assistentes, trazendo alunos de fora da cidade, reformando currículos ultrapassados, incentivando agressivamente a aposentadoria precoce de pesquisadores desmotivados.

\footnotetext{
* Professora do Programa de Pós-Graduação em Direito da Pontifícia Universidade Católica do Rio de Janeiro (PUC-Rio). Doutora em Ciência Política pelo Instituto Universitário de Pesquisas do Rio de Janeiro (IUPERJ), em 1998.

${ }^{1}$ A Marca Humana (Human Stain-2000), de Philip Roth, conclui a trilogia da qual fazem parte A Pastoral Americana (American Pastoral-1997) e Casei com um Comunista (I Married a Comunist-1998), textos que apresentam um painel da sociedade americana nas últimas décadas. Philip Milton Roth nasceu em 1933, em Newark, Nova Jersey. Descendente de judeus, é um dos maiores escritores norte-americanos contemporâneos. Autor de mais de vinte romances, tem oito livros traduzidos para o português e publicados no Brasil pela Companhia das Letras.
} 


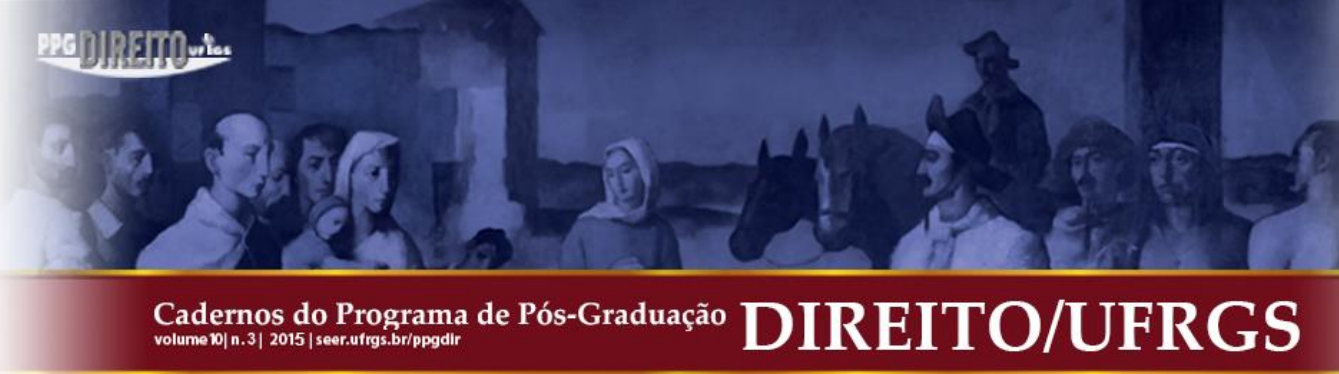

filhos de Coleman, os prudentes e insistentes conselhos do seu advogado, as ameaças anônimas de Delphine Roux e a incansável perseguição de Lester Farley, o atormentado exmarido de Faunia, que, finalmente, joga seu caminhão contra o carro em que está o casal, provocando o acidente que será fatal para ambos.

Nathan Zuckerman é o narrador-personagem deste romance. Com 65 anos, vizinho de Coleman, impotente em função do tratamento de um câncer na próstata, Zuckerman, alter ego de Philip Roth e velho conhecido dos seus romances, é quem descobre, logo após o enterro dos amantes, o segredo que Coleman jamais revelou a ninguém. O brilhante intelectual, especialista em Sófocles e que tudo sabia sobre a Ilíada, era negro. Um negro sem traços étnicos visíveis, com uma tonalidade de pele que lhe permitia passar-se por um branco judeu com raízes no Oriente Médio.

A partir daí é Nathan Zuckerman o autor do relato. É ele quem nos conta que Coleman Silk nascera negro, no seio de uma família negra e que por muito tempo se identificara como negro. Aluno brilhante, atleta excepcional, orador da turma no ensino médio, Coleman sempre teve o pai a protegê-lo do perigo da discriminação racial. Mas quando se muda para Washington para frequentar a Howard University, uma instituição exclusiva para negros, passa a enfrentar a humilhação, os obstáculos, a segregação. Sentindo-se por vezes um homem invisível, agredido fisicamente em outras situações, Coleman se desespera quando Steena Palsson, americana de sangue dinamarquês, seu primeiro e mais intenso amor, o abandona quando descobre a verdade sobre sua origem, dizendo, simplesmente: "desculpe, mas não consigo". Nesse momento, que coincide com a morte de seu pai, Coleman Silk toma uma decisão e, movido por uma extraordinária energia, sente-se livre para ser o que quiser; na verdade, sente-se agora livre não apenas de seu pai, mas de tudo aquilo que ele havia sido obrigado a suportar. Se o fracasso e a derrota, com suas marcas de dor, mágoa e vergonha, haviam acompanhado os passos de seu pai ao longo da vida, Coleman Silk estava livre para seguir adiante sem permitir que uma sociedade preconceituosa lhe determinasse o destino. E foi assim que, aos 26 anos, assumindo a brutalidade do ato mais brutal de que já fora capaz, Coleman procura a sua tão dedicada e amorosa mãe para dizer-lhe que decidira tornar-se branco e que, por isso, jamais voltaria a vê-la.

Nos anos seguintes Coleman casa-se com Iris Gittelmann, branca e judia, conclui seus estudos na New York University, tem quatro filhos sem que nenhum deles demonstre o menor sinal do seu segredo e constrói uma brilhante vida acadêmica na Universidade de Athena. 


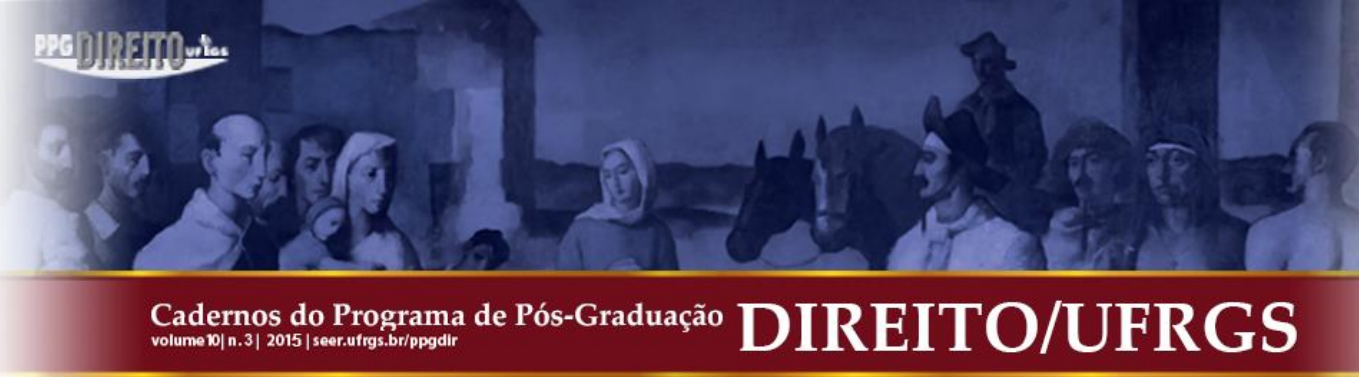

Coleman finalmente havia conseguido aquilo que desde sempre desejara: ser livre. Identificarse como branco simplesmente lhe pareceu a opção mais natural para alguém com sua cor de pele, seu temperamento e suas opiniões. Em sua escolha não havia a intenção de insultar ninguém ou imitar alguém que considerasse superior ou mesmo realizar algum protesto. Além disso, como muitas das pessoas que ele conhecia sempre o tomavam por judeu, tinha sido bastante fácil explicar que Silk era uma forma atenuada de Silberzweig, imposta a seu pai por um simpático funcionário da imigração.

A decisão de Coleman havia sido tomada contra dois grupos: o maior, pois não podia permitir que lhe impusesse seu preconceito; mas igualmente não podia admitir que o menor lhe impusesse a sua ética. Contra um nós moral coercitivo, englobante, histórico e inevitável, Coleman havia optado pela agilidade e pela singularidade de um eu livre. Isso significava não aceitar o destino que lhe estava traçado, desvencilhar-se de suas origens e reinventar a si mesmo como um simples membro - sem filiações - da raça humana.

\section{TRAGÉDIA, IDENTIDADE E TRAIÇÃO}

Os dicionários costumam descrever as tragédias como dramas que retratam graves conflitos entre o protagonista e alguma força superior, cuja conclusão desperta no leitor sentimentos de piedade ou horror. Em A Marca Humana, Philip Roth nos coloca, sem dúvida, diante de uma tragédia. $\mathrm{O}$ drama retrata a luta individual de um personagem em luta contra $\mathrm{o}$ seu destino. Coleman Silk, o protagonista, tal como os heróis gregos que tanto admira, pretende triunfar sobre forças sociais poderosas, e recusa-se a admitir que não tem controle sobre o curso de sua vida.

Como professor apaixonado pela literatura clássica, Coleman tomba como um herói na batalha. Nem mesmo quando é acusado de racismo por seus colegas acadêmicos, Coleman revela a verdade sobre sua origem. Ele vive e morre dentro de sua própria estrutura narrativa, permanecendo invisível para todos. Philip Roth, que não poupa referências a Sófocles e aos mitos gregos ao longo do texto, utiliza o segredo de Coleman para transformá-lo em um personagem análogo aos heróis clássicos.

Tal como Édipo, Coleman acredita que está livre da sua sina. Supõe que ao converterse em um homem branco escapará do lugar que lhe foi designado pela sociedade norteamericana. Se Édipo não quer voltar para Corinto porque acredita que assim não se realizará a 


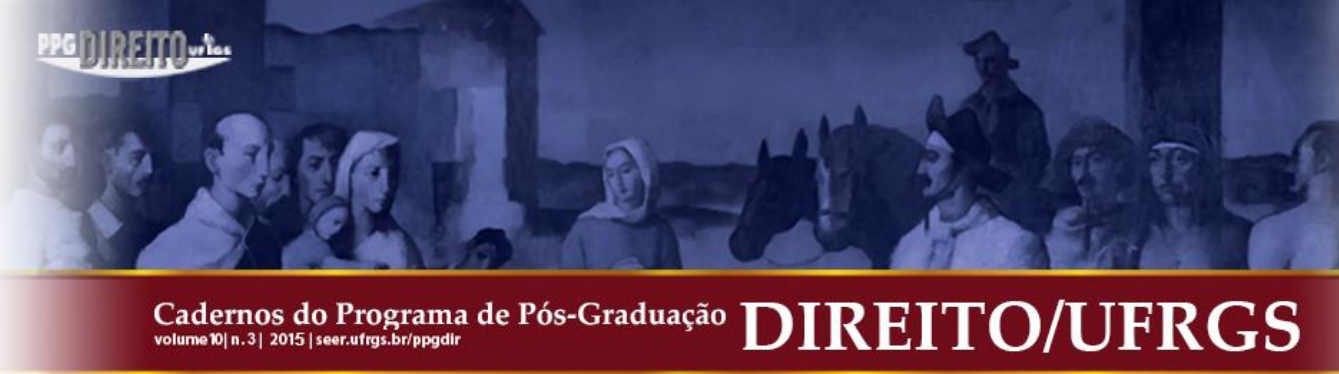

profecia do oráculo, Coleman igualmente recusa a identidade negra para impedir que o seu destino se cumpra. Coleman e Édipo também compartilham outra dimensão da tragédia. Para o professor, a decisão de viver como branco resulta na simbólica morte de sua mãe, já que ele sabe que jamais poderá reencontrá-la. O jovem príncipe, para sua desgraça, mata o seu pai sem conhecê-lo - quando se envolve em uma luta; Coleman, deliberadamente, repete todos os dias o assassinato de sua mãe.

Os deuses ou o destino são igualmente irônicos com Édipo e Coleman. O príncipe foge para Tebas para escapar da sua sorte; mas a maldição que recai sobre a cidade só será afastada se Édipo dela for banido. Da mesma forma, Coleman tenta escapar de uma sociedade discriminatória apenas para ser punido por uma comunidade acadêmica provinciana que, movida por um sentimento de vingança, o acusa de racista. Finalmente, tanto Coleman como Édipo têm suas marcas humanas. A origem negra, num caso, e a cicatriz no calcanhar, no outro, são os registros indeléveis que cumprem a função de inviabilizar todas as tentativas de purificação.

Em A Marca Humana não é apenas Coleman que redefine a sua identidade com a esperança de melhor sobreviver. Faunia Farley também constrói uma personagem. Fingindo ser analfabeta, acredita que ao assumir voluntariamente essa desvantagem pode melhor desempenhar o papel da marginalizada. Essa característica é, para ela, mais adequada à função de faxineira da Universidade de Athena do que deixar evidente para todos a sua alma crítica e altiva. Delphine Roux, da mesma forma, desempenha um papel e quer se fazer passar por alguém que não é. Em um ambiente acadêmico dominado por homens, ela, mulher e estrangeira, mede o seu sucesso por meio de sua capacidade de assimilação. A personagem da francesa desenraizada que faz a si mesma é perfeita para Delphine, ainda que para isso seja necessário reprimir a sexualidade e os afetos em favor do intelecto. Há, todavia, uma diferença entre a forma como Faunia e Delphine constróem suas próprias personagens. Se Delphine foge dos estereótipos que sobre ela poderiam ser criados - "diferente" porque estrangeira ou "incompetente" porque bonita - Faunia faz questão de ser identificada com todos os estereótipos vinculados ao seu papel. Tanto uma como outra, no entanto, tentam apagar as pistas que poderiam levar a que fossem vistas como pessoas iguais ou diferentes daquilo que efetivamente são.

Ao descrever pessoas que redefinem a sua identidade, Philip Roth universaliza o particular para falar das múltiplas formas de discriminação racial, social e religiosa existentes 


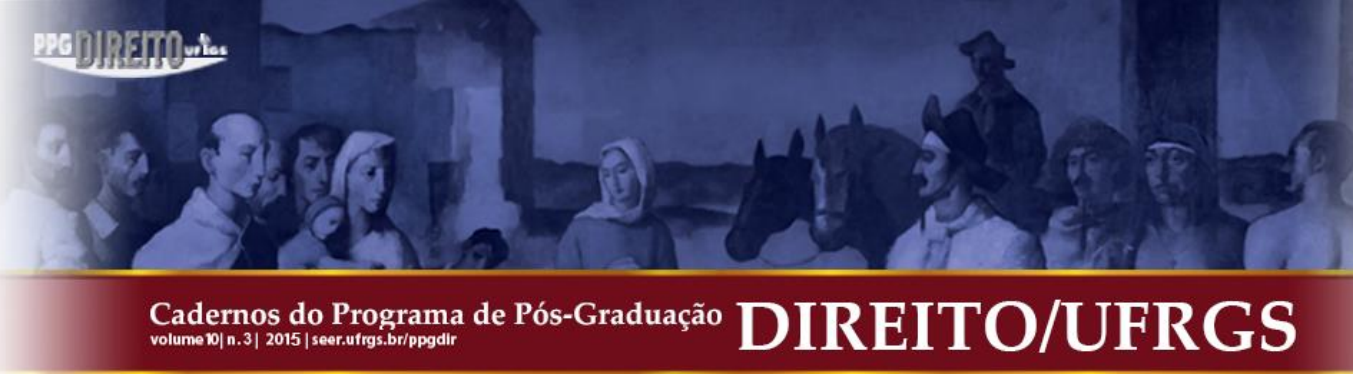

De qualquer forma, não há indignidade ou traição na decisão de Coleman de reinventar a si mesmo. Ele simplesmente pretende ser independente e livre. Nem negro, nem branco, nem judeu, apenas alguém que toma o futuro em suas próprias mãos ao invés de permitir que múltiplas comunidades preconceituosas determinem seu destino. Soberano na invenção de seu próprio self, Coleman faz a opção contrária a de seu irmão, Walter, que confia fortemente em suas próprias tradições. Enquanto Walter pretende dar prosseguimento de forma não problemática a algo que outros já iniciaram porque acredita que seus antepassados não pretendem enganá-lo, Coleman opta por um distanciamento reflexivo em relação às tradições que conformam sua identidade. Em outras palavras, Coleman opta por "pular fora".

\section{AUTONOMIA OU O DIREITO DE "PULAR FORA"}

Os mundos culturais apenas sobrevivem quando os indivíduos que os compartilham, ainda que obrigados a confrontarem-se com culturas distintas, optam por regenerar a força de suas identidades culturais. Isso significa dizer que não podemos aplicar às culturas o mesmo tratamento dispensado pela ecologia à preservação das espécies. Nem os legados culturais podem ser impostos, nem protegidos de avaliações críticas, especialmente porque nas sociedades democráticas contemporâneas a relação com o estranho é inevitável. ${ }^{2}$

Não há dúvida de que nossas identidades individual e social são constituídas por meio da internalização e da adoção de papéis e regras sociais que são transmitidas pela via de costumes, valores e tradições concretas. Sabemos, no entanto, que um dos traços fundamentais da modernidade é a configuração do indivíduo como sujeito capaz de autorreflexão e crítica. Nesse sentido, ainda que nossa identidade se constitua a partir da sua inserção em uma forma de vida compartilhada - na medida em que aprendemos a nos relacionar com os outros e com nós mesmos por meio de uma rede de reconhecimento recíproco que se estrutura por meio da linguagem - isso não pode significar uma lógica de aprisionamento. Cada um de nós têm a capacidade de se comportar reflexivamente em relação à própria subjetividade, endossando valores ou libertando-se de compromissos, ilusões ou fantasias.

Cadernos do Programa de Pós-Graduação em Direito PPGDir./UFRgS | Edição Digital | Porto Alegre | Volume X | Número 3 | 2015 | P. $53-64$ 


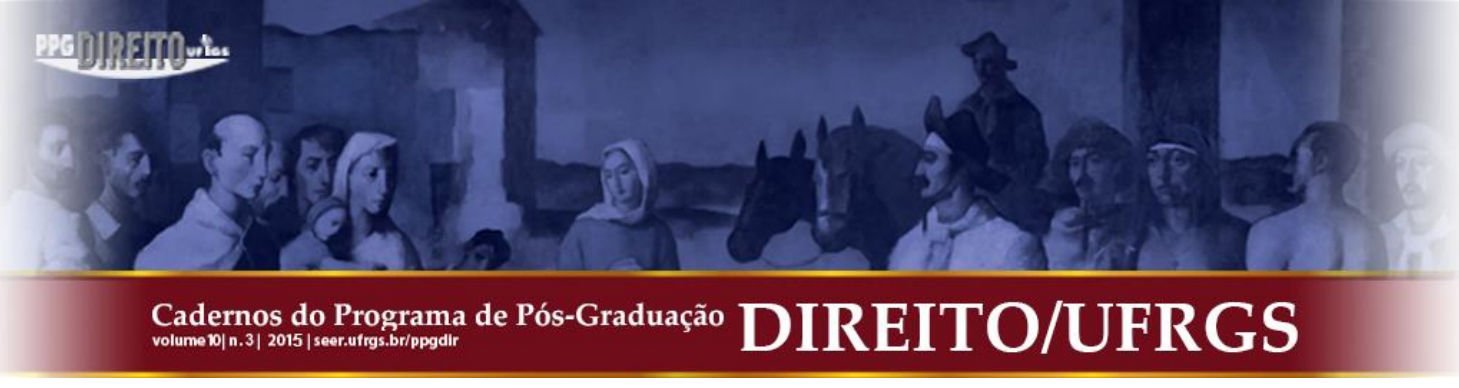

Em A Marca Humana, são diferentes as relações estabelecidas por Coleman e Walter Silk com suas identidades culturais. Enquanto Coleman prefere identificar-se com algum tipo de cosmopolitismo, Walter não encontra encantos fora do particularismo. De um lado, o eu, a singularidade, o autoconhecimento, a vertigem; de outro, o nós, a homogeneidade, a internalização, a segurança. É evidente que Coleman, ao questionar as normas do mundo em que vive, o faz a partir de convicções que integram o seu próprio contexto cultural. Ainda que isso possa nos levar a imaginar que Coleman coloca em questão a sua própria existência quando critica as formas de vida nas quais sua identidade foi constituída, não devemos dramatizar os limites que a eticidade do mundo da vida nos apresenta. Ter a capacidade de refletir criticamente sobre a faticidade das instituições e normas presentes no mundo da vida certamente não se traduz no questionamento da própria existência. Em outras palavras, uma ação reflexiva sobre a própria subjetividade pode simplesmente significar autonomia e, no caso de Coleman, o direito de "pular fora".

Para muitos, no entanto, o direito de "pular fora", especialmente quando estamos diante de alguém que integra um grupo historicamente marginalizado - Coleman é negro representa uma ação de infidelidade em relação a si mesmo. Não haveria como "pular fora" sem que isso representasse uma violação do ideal de autenticidade, ou seja, um ataque à dimensão original da própria identidade. Em outras palavras, Coleman não estaria moralmente valorizando a importância de ser autêntico em relação a si mesmo. Ao invés, Walter, irmão de Coleman, manteria sua "identidade intacta", 3 , seu compromisso com a autenticidade, na medida em que não abre mão de sua herança cultural.

Quando Philip Roth nos conta a história de um homem cuja existência está baseada tanto em uma negação como em uma afirmação de si mesmo, a história de um homem que triunfa porque constrói aquilo que desejava, fala-nos de um sujeito que, pela via da reflexão e da crítica, rompe com a validade intuitiva de seus valores. Estamos, portanto, diante da ideia de que todos os seres humanos têm autonomia e o mesmo valor moral. Ao mesmo tempo, esse ideal não está baseado em nenhuma visão de mundo particular, pois esse sujeito moral autônomo tem a capacidade de formular essa ética por sua própria conta. Em outras palavras,

\footnotetext{
2 Ver, a respeito, HABERMAS, Jürgen Habermas. Struggles for Recognition in the Democratic Constitutional State. In: GUTMAN, Amy (ed.). Multiculturalism. Princeton: Princeton University Press, 1994.

${ }^{3}$ Ver, a respeito, FRASER, Nancy; HONNETH, Axel. Redistribución o Reconocimiento? Madrid: Ediciones Morata, 2006.
} 


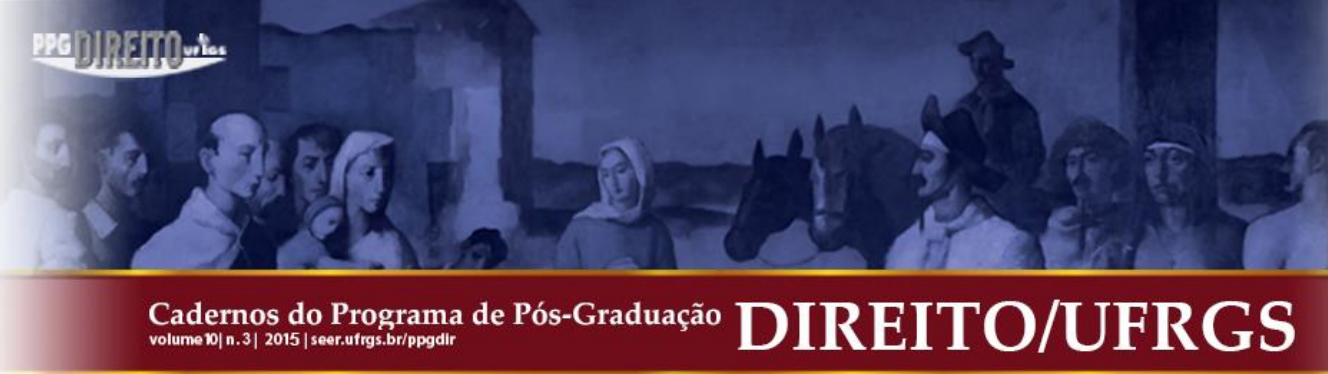

o direito de "pular fora" não viola o ideal de autencidade, pois a nossa identidade não é apenas algo com que inevitavelmente nos defrontamos, mas também é nosso próprio projeto. ${ }^{4}$

Resta-nos, finalmente, indagar sobre as consequências normativas desse compromisso com uma autonomia moral que nos garanta o direito de "pular fora". Necessitamos, sem dúvida, de uma teoria da justiça ancorada em um ponto de vista deontológico que assegure um sistema de direitos capaz de transformar esse indivíduo moral autônomo em autor e sujeito de direito. Esse processo de atribuição de direitos não pode estar simplesmente ancorado em uma herança cultural comum. É preciso esclarecer desde logo que o processo de atribuição de direitos não é posterior ao sentimento de pertencimento a uma comunidade, porque o sistema de direitos não pode ser considerado apenas uma expressão valorativa de um sistema cultural específico. Ainda que tenha surgido, enquanto ideia normativa, em um mundo particular de cultura, isto não significa que não possa ser visto como o resultado de um processo reflexivo a partir do qual os indivíduos podem tomar certa distância em relação às suas próprias tradições e aprender a entender o próximo a partir de sua própria perspectiva.

Coleman Silk jamais teria autodeterminação para redesenhar sua própria existência se Philip Roth acreditasse que as identidades culturais estão delimitadas por nítidas fronteiras. Isso impediria qualquer movimento emancipatório voltado para a remoção de barreiras ao exercício de escolhas autônomas. É exatamente por não acreditar que o processo histórico conforma inteiramente as individualidades - pois os sujeitos não são apenas seres concretamente situados em uma tradição particular - que Roth permite que Coleman rompa com os valores que unem coletivamente os membros de sua própria comunidade de origem. Em outras palavras, o sistema de direitos que assegura a Coleman a possibilidade de "pular fora” não deriva de qualquer tradição cultural particular, mas é sim o resultado daquela ideia que é central no pensamento de Rousseau e Kant, ou seja, a de que o ordenamento normativo é resultado da autonomia de sujeitos de direito associados. Ou, como fala Habermas, estamos falando de um modelo que supõe um debate público no qual pessoas livres e iguais definem quais direitos devem mutuamente reconhecer se pretendem legitimamente regular sua vida em comum por meio do direito.

Ao mesmo tempo, esse sistema de direitos - desvinculado de qualquer herança cultural e cuja função é garantir a autonomia moral dos indivíduos - também assegura a integridade de

\footnotetext{
${ }^{4}$ Ver, a respeito, HABERMAS, Jürgen. La Necessidad de Revisión de la Izquierda. Madrid: Editorial Tecnos, Cadernos do Programa de Pós-Graduação em Direito PPGDir./UFRGS | Edição Digital | Porto Alegre | Volume X | Número 3 | 2015 | P. 53 -64
} 


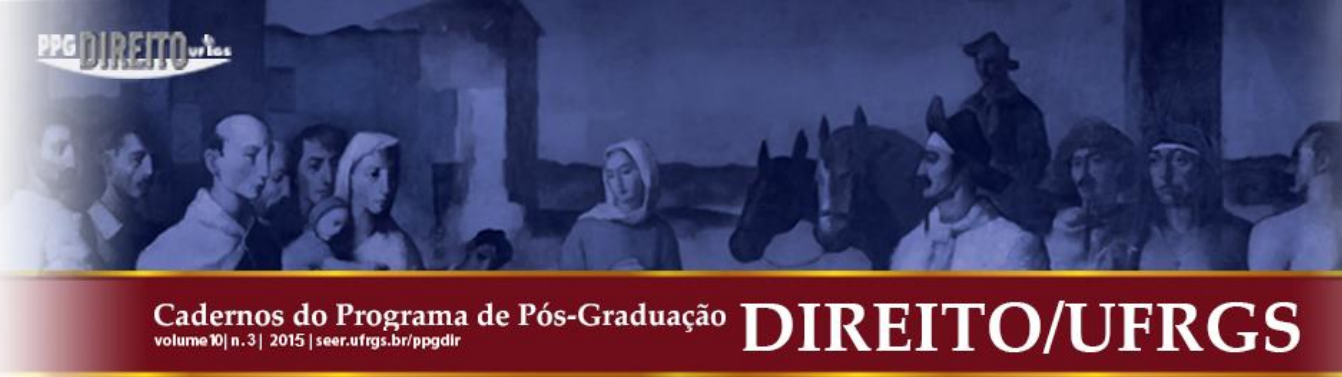

cada um nos contextos sociais e culturais nos quais a sua identidade se constitui. Isso significa dizer que o princípio do igual respeito - fundamento do sistema de direitos - não é cego ou ineficaz em face da discriminação e das desigualdades sociais e culturais. O compromisso com a cidadania igualitária não é incompatível com a garantia de direitos culturais demandados e introduzidos sob o signo das "políticas de reconhecimento". Afinal, se uma sociedade democrática é uma comunidade de cidadãos livres e iguais, o ordenamento jurídico não pode ser um mero distribuidor de liberdades de ação de tipo privado. A distribuição dos direitos só pode ser igualitária se os cidadãos - na qualidade de legisladores - estabelecem um consenso acerca dos critérios por meio dos quais o igual vai receber um tratamento igual, enquanto que o desigual um tratamento desigual.

Se estamos falando de uma sociedade democrática em que os cidadãos asseguram a todos, como legisladores, esferas de liberdade em face da autodeterminação moral de cada um, não há dúvidas que tanto Coleman como Walter Silk não encontrarão obstáculos à realização de seus projetos pessoais de vida. O sistema de direitos que assegura os direitos culturais sem os quais Walter Silk não pode dar continuidade às tradições de seus antepassados é o mesmo sistema de direitos que permite a Coleman Silk "pular fora".

Finalmente, analisando a trajetória do protagonista de Philip Roth, nos resta perguntar sobre a inexorabilidade da marca humana. Coleman Silk teria ou não escapado do seu destino? A sua própria história terminou por alcançá-lo por meio da acusação de racismo? A marca humana significa que não podemos escapar daquilo que é essencial e, por vezes, escuro no interior de nós mesmos? Ou a marca humana estaria mais bem representada por uma vulnerabilidade que não resistiu, no caso de Coleman, à violência de Lester Farley? Qualquer que seja a resposta, ela não é essencial. Ao final da trajetória, morremos todos. Coleman conseguiu "pular fora" e construir autonomamente o seu percurso. É isso o que importa.

\section{REFERÊNCIAS}

FRASER, Nancy; HONNETH, Axel. Redistribución o Reconocimiento? Madrid: Ediciones Morata, 2006.

1996.

Cadernos do Programa de Pós-Graduação em Direito PPGDir./UFRgS | Edição Digital | Porto Alegre | Volume X | Número 3 | 2015 | P. 53 -64 


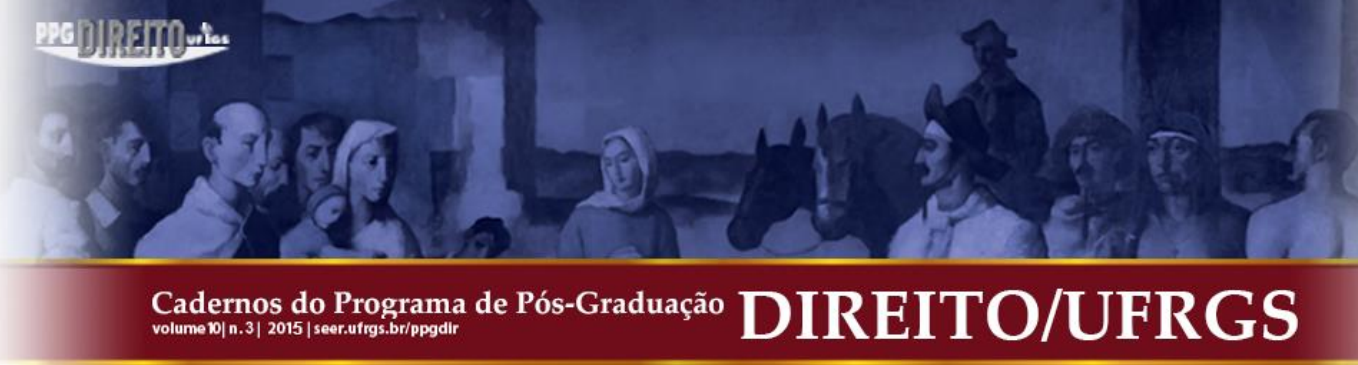

HABERMAS, Jürgen. Struggles for Recognition in the Democratic Constitutional State. In: GUTMAN, Amy (ed.). Multiculturalism. Princeton: Princeton University Press, 1994.

HABERMAS. Jürgen. La Necessidad de Revisión de la Izquierda. Madrid: Editorial Tecnos, 1996.

HABERMAS. Jürgen. Remarks on Erhard Denninger's Triad of Diversity, Security, and Solidarity. Constellations. v. 7, n. 4, Blackwell Publishers, 2000.

POSNOCK, Ross. Purity and Danger: On Philip Roth. Raritan Review. n. 21. v. 2. Outono de 2001.

ROTH, Philip. A Marca Humana. São Paulo: Companhia das Letras, 2000.

SAFER, Elaine B. Tragedy and Farce in Roth's The Human Stain. Critique. n. 3. v. 43. Primavera de 2002.

SÓFOCLES. Édipo Rei. São Paulo, Editora Scipione Ltda., 2002.

TAYLOR, Charles. El Multiculturalismo y la Política del Reconocimiento. México: Fondo de Cultura Económica, 1993.

Submissão: 20/11/2015 Aceito para Publicação: 20/11/2015 
